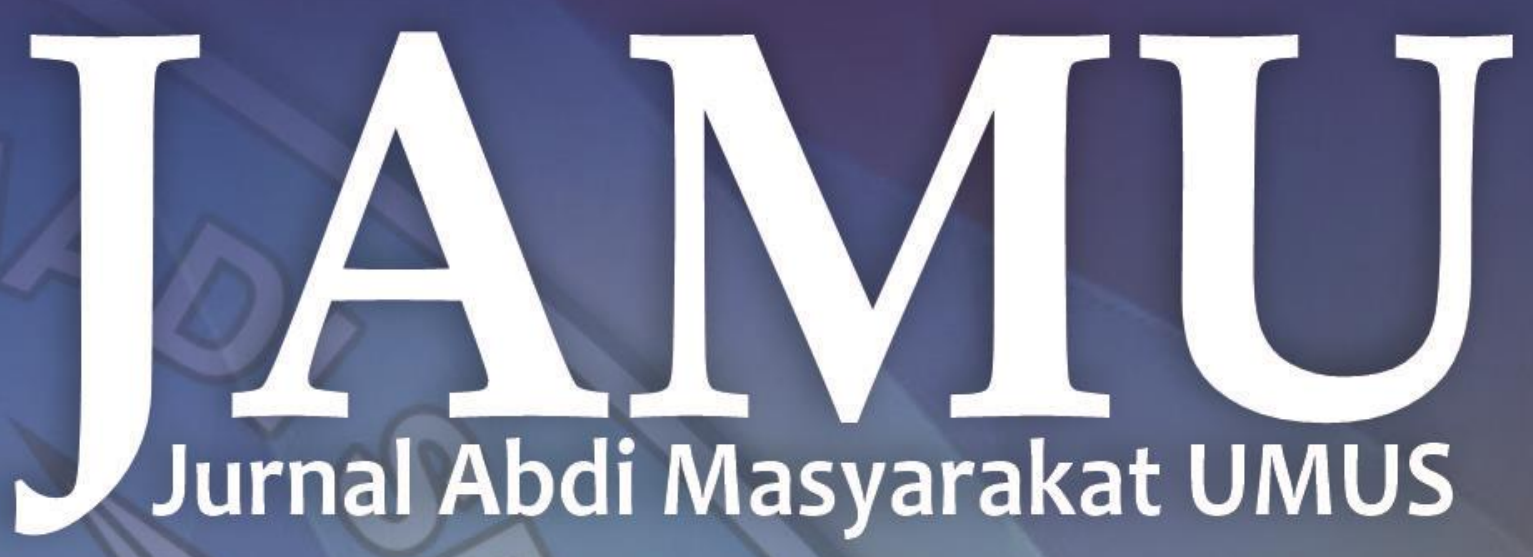




\section{EDITOR IN CHIEF}

Ubaedillah, M.Pd

\section{MANAGING EDITOR}

Harliana, ST., M.Cs

\section{PRINCIPAL CONTACT}

Rifatul Masrikhiyah, S.Tp., M.Si

\section{SUPPORT CONTACT}

Laelia Nurpratiwiningsih, M.Pd

\section{MITRA BESTARI (STAFF AHLI)}

Dr. Roby Setiadi, S.Kom., M.M (Universitas Muhadi Setiabudi, Brebes)

Otong Saeful Bachri, S.Kom., M.Kom (Universitas Muhadi Setiabudi, Brebes)

Dr. Moh. Toharudin, M.Pd (Universitas Muhadi Setiabudi, Brebes) Atikah Mumpuni, M.Pd (Universitas Muhadi Setiabudi, Brebes)

Dr. Heru Ismanto, S.Si., M.Cs (Universitas Musamus Merauke, Papua) Dr. Wuri Wuryandani, M.Pd (Universitas Negeri Yogyakarta)

Dr. Nanik Sulistyani, M.Si., Apt (Universitas Ahmad Dahlan, Yogyakarta)

Dina Rahayuning Pangestuti, S.TP., M.Gizi (Universitas Diponogoro) Jasanta Peranginangin, S.E., M.M (Sekolah Tinggi Pariwisata Sahid Surakarta)

Dr. Lili Karmela Fitriani, S.E., M.Si (Universitas Kuningan, Jawa Barat)

\section{PENANGGUNGJAWAB :}

Rektor Universitas Muhadi Setiabudi Brebes

\section{ALAMAT PENYUNTING:}

LP3M Universitas Muhadi Setiabudi Brebes.

Jalan Pangeran Diponogoro KM 2 Wanasari Brebes - Jawa Tengah 52252. Telp (0283) 6199000 


\section{JAMU}

Jurnal Abdi Masyarakat UMUS

\section{KATA PENGANTAR}

Assalamualaikum Wr, Wb

Puji syukur kehadirat Allah SWT atas anugrahnya sehingga jurnal edisi kali ini dapat terbit. Sebelumnya kami ingin mengucapkan terimakasih banyak kepada dosen/peneliti/profesi yang telah mengirimkan artikelnya kepada dewan redaksi untuk dapat dipublish pada jurnal yang kami kelola. Semua artikel yang masuk kepada dewan redaksi telah melalui proses review oleh mitra bestari dan tim dewan redaksi, segala proses revisi dan redaksional juga telah dilakukan oleh penulis sebelum jurnal ini diterbitkan. Segala bentuk kritik dan saran yang membangun dari pembaca / peneliti yang dikirimkan sangat kami harapkan demi melakukan pembenahan jurnal yang kami kelola. Akhir kata kami menghaturkan terimakasih banyak kepada semua pihak yang sudah terlibat dalam proses penerbitan jurnal ini.

Wassalamualaikum wr wb.

Ketua Dewan Redaksi 


\section{DAFTAR ISI}

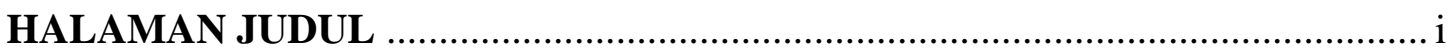

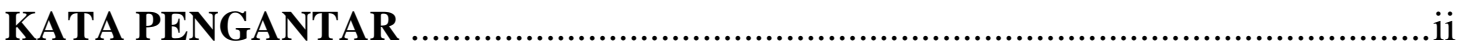

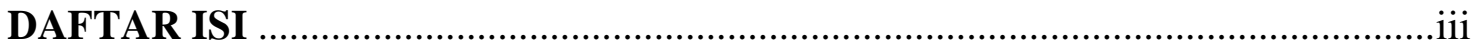

Pemberdayaan Anak Usia Sekolah Dalam Menumbuhkan Nilai Karakter Melalui Strategi Pembiasaan Di PPSA Tegal

Moh. Toharudin ${ }^{1}$, Laelia Nurpratiwiningsih ${ }^{2}$, Gian Fitralisma ${ }^{3}$

${ }^{(1,2)}$ Program Studi Pendidikan Guru Sekolah Dasar, Fakultas Keguruan dan Ilmu Pendidikan Universitas Muhadi Setiabudi

${ }^{3}$ Program Studi Manajemen, Fakultas Ekonomi dan Bisnis, Universitas Muhadi Setiabudi) $\quad$ 1-7

Menstimulasi Kemampuan Berbicara Pada Anak Usia Dini Berbasis Media Dongeng Agnes Apryliana ${ }^{1}$, Kiki Purwati ${ }^{2}$

${ }^{(1,2)}$ Program Studi Pendidikan Bahasa dan Sastra Indonesia, Fakultas Keguruan dan Ilmu Pendidikan, Universitas Muhadi Setiabudi)

Pemanfaatan E-Commerce Terhadap Penjualan Kendang Jimbe Blitar Harliana $^{1)}$, Roby Setiadii ${ }^{2}$, Otong Saeful Bachri ${ }^{3)}$, Khalid Iskandar ${ }^{4)}$, Gagas Prasetya ${ }^{5)}$ ${ }^{(1,3,5)}$ Program Studi Teknik Informatika, Fakultas Teknik, Universitas Muhadi Setiabudi ${ }^{2,4)}$ Program Studi Manajemen, Fakultas Ekonomi dan Bisnis, Universitas Muhadi Setiabudi) 15-20

Manajemen Tatakelola BUMDES: Mengelola Pemasaran Produk

Andi Yulianto ${ }^{1)}$, Mukson ${ }^{2)}$, Otong Saeful Bachri ${ }^{3)}$, Slamet Bambang Riono ${ }^{4)}$, Yenny Ernitawati ${ }^{5)}$ ${ }^{(1,2,4)}$ Program Studi Manajemen, Fakultas Ekonomi dan Bisnis, Universitas Muhadi Setiabudi ${ }^{5)}$ Program Studi Akuntansi, Fakultas Ekonomi dan Bisnis, Universitas Muhadi Setiabudi)

${ }^{3)}$ Program Studi Teknik Informatika, Fakultas Teknik, Universitas Muhadi Setiabudi)

Penggunaan Kartu Huruf dan Peramainan Mencari Kartu Huruf Untuk Peningkatan Pengenalan Huruf

Muhammad Toha $^{1)}$, Armyta Puspitasari ${ }^{2}$, Ubaedillah ${ }^{3)}$, Farhan Saefudin Wahid ${ }^{4)}$, Laelia Nurpratiwiningsih ${ }^{5}$

${ }^{(1,3)}$ Program Studi Pendidikan Bahasa dan Sastra Indoensia, Fakultas Keguruan dan Ilmu Pendidikan, Universitas Muhadi Setiabudi,

2)Teknologi Bangunan dan Jalur Perkretaapian, Politeknik Perkretaapian Indonesia,

${ }^{4,5}$ Program Studi Pendidikan Guru Sekolah Dasar, Fakultas Keguruan dan Ilmu Pendidikan, Universitas Muhadi Setiabudi)

${ }^{3)}$ Program Studi Manajemen, Fakultas Ekonomi dan Bisnis, Universitas Muhadi Setiabudi)

$28-33$ 


\section{Menumbuhkan Sikap Sadar Lingkungan Bagi Anak Usia Sekolah Dasar}

Laelia Nurpratiwiningsih ${ }^{1)}$, Teguh Arifianto ${ }^{2)}$, Wildan Qosid ${ }^{3)}$, Ubaedillah ${ }^{4)}$

(1,3)Program Studi Pendidikan Guru Sekolah Dasar, Fakultas Keguruan dan Ilmu Pendidikan, Universitas Muhadi Setiabudi,

${ }^{2)}$ Teknologi Elektro Perkretaapian, Politeknik Perkretaapian Indonesia,

$\left({ }^{4}\right.$ Program Studi Pendidikan Bahasa dan Sastra Indonesia, Fakultas Keguruan dan Ilmu Pendidikan,

Universitas Muhadi Setiabudi)

Peningkatan Pengetahuan Mengenai Manfaat Pangan Probiotik dan Prebiotik Bagi Kesehatan

Rifatul Masrikhiyah ${ }^{1)}$, Henry Widya Prasetya ${ }^{2)}$, Ubaedillah $^{3)}$, Rifqi Ferry Balfas ${ }^{4}$, Susi Yulianingsih ${ }^{5)}$ ${ }^{1,5}$ Program Studi Ilmu Gizi, Fakultas Kesehatan, Universitas Muhadi Setiabudi,

${ }^{2)}$ Teknologi Mekanika Perkretaapian, Politeknik Perkretaapian Indonesia,

${ }^{3}$ Program Studi Pendidikan Bahasa dan Sastra Indonesia, Fakultas Keguruan dan Ilmu Pendidikan, Universitas Muhadi Setiabudi,

4)Program Studi Ilmu Gizi, Fakultas Ilmu Kesehatan, Universitas Muhadi Setiabudi) $\quad$ 42-46

\section{Pelatihan Wawancara Kerja Dalam Bahasa Inggris Bagi Siswa SMK Menggunakan}

Metode Demonstrasi

Ubaedillah $^{1)}$, Damar Isti Pratiwi ${ }^{2)}$, Mukson $^{3)}$, Rifatul Masrikhiyah ${ }^{4)}$, Laelia Nurpratiwiningsih ${ }^{5)}$

( ${ }^{1}$ Program Studi Pendidikan Bahasa dan Sastra Indonesia, Fakultas Keguruan dan Ilmu Pendidikan, Universitas Muhadi Setiabudi,

2) Teknologi Mekanika Perkretaapian, Politeknik Perkretaapian Indonesia.

${ }^{3}$ Program Studi Manajemen, Fakultas Ekonomi dan Bisnis, Universitas Muhadi Setiabudi,

${ }^{4)}$ Program Studi Ilmu Gizi, Fakultas Ilmu Kesehatan, Universitas Muhadi Setiabudi

${ }^{5)}$ Program Studi Guru Sekolah Dasar, Fakultas Keguruan dan Ilmu Pendidikan, Universitas Muhadi Setiabudi) 


\title{
PENGGUNAAN KARTU HURUF DAN PERMAIANAN MENCARI KARTU HURUF UNTUK PENINGKATAN PENGENALAN HURUF
}

\author{
Muhamad Toha ${ }^{1}$, Armyta Puspitasari ${ }^{2}$, Ubaedillah ${ }^{3}$, Farhan Saefudin Wahid ${ }^{4}$, Laelia \\ Nurpratiwiningsih ${ }^{5}$ \\ ${ }^{1,3}$ Program Studi Pendidikan Bahasa dan Satra Indonesia, Fakultas Keguruan dan Ilmu \\ Pendidikan Universitas Muhadi Setiabudi Brebes, Indonesia \\ ${ }^{2}$ Teknologi Bangunan dan Jalur Perkretaapian, Politeknik Perkretaapian Indonesia, \\ ${ }^{4,5}$ Program Studi Pendidikan Guru Sekolah Dasar, Fakultas Keguruan dan Ilmu Pendidikan \\ Universitas Muhadi Setiabudi Brebes, Indonesia \\ e-mail: ${ }^{1}$ muhamadtoha1017@gmail.com, ${ }^{2}$ armyta@ppi.ac.id, ${ }^{3}$ ubaedillah2@gmail.com
}

${ }^{4}$ Farhan.sw@umus.ac.id ${ }^{5}$ laelia@umus.ac.id

\begin{abstract}
Abstrak
The purpose of this observation is to find out the increase in the ability to recognize letters in the children of group A PAUD Gemar Ilmu Regency of Brebes through letter card media. The subjects of this observation were group A children of 22 students. Data collection techniques are carried out through observation, checklist and interview. The results of the observation showed an increase in the ability to recognize letters in PAUD Gemar Ilmu students in group A after learning using letter card media, which initially was in the percentage of $45.44 \%$ to $86.26 \%$. Thus the use of letter card media in learning to recognize letters can improve the ability to recognize letters in the children of group A PAUD Gemar Ilmu Regency of Brebes.

Keywords: Ability to Know Letters, Early childhood, Letter Card
\end{abstract}

\section{PENDAHULUAN}

Menurut Undang-Undang No. 20 SISDIKNAS 2003 bab 1 ayat 14 menyatakan bahwa pendidikan anak usia dini adalah suatu upaya pembinaan yang ditujukan kepada anak sejak lahir sampai dengan usia 6 tahun yang dilakukan melalui pemberian rangsangan pendidikan untuk membantu pertumbuhan dan perkembangan jasmani dan rohani agar anak memiliki kesiapan dalam memasuki pendidikan lebih lanjut. Penyelenggaraan pendidikan bagi anak usia dini dapat dilakukan dalam bentuk formal, nonformal dan informal (Sujiono, 2009:303).

Pendidikan Anak Usia Dini (PAUD) adalah upaya pembinaan yang ditujukan kepada anak sejak lahir sampai usia 6 (enam) tahun yang dilakukan melalui pemberian rancangan pendidikan untuk membantu pertumbuhan dan perkembangan jasmani dan rohani agar anak memiliki kesiapan dalam memasuki pendidikan lebih lanjut (Permendikbud No 137 tahun 2014). Pendidikan anak usia dini merupakan pendidikan formal jenjang pertama yang dilaksanakan pada sistem pendidikan di Indonesia. Pembelajaran yang terjadi di PAUD adalah proses interaksi antar anak didik, antara anak didik dan pendidik dengan melibatkan orang tua serta sumber belajar pada suasana belajar dan bermain di satuan atau program PAUD. Sedangkan aspek pengembangan yang harus dijadikan pembelajaran di PAUD, adalah aspek agama dan moral, kognitif, fisik-motorik, sosial emosional, seni dan bahasa (Permendikbud No 137 tahun 2014).. Bahasa menjadi salah satu aspek yang diperhatikan dalam proses perkembangan anak. Oleh karena itu, melatih kemampuan 
anak untuk menggunakan bahasa dengan baik dan benar sejak dini menjadi kewajiban bagi lingkungan di sekitar anak tersebut agar anak mampu mengekspresikan dirinya dengan baik. Pengembangan bahasa anak akan memudahkan anak untuk mengungkapkan pikiran dan dapat berkomunikasi secara efektif. Pada anak usia 4-5 tahun indikator pencapaian perkembangan keaksaraan yang harus dikuasai adalah mengenal simbolsimbol, mengenal suara-suara hewan/benda yang ada di sekitarnya, membuat coretan yang bermakna, meniru (menuliskan dan mengucapkan) huruf A-Z (Permendikbud No 137 tahun 2014). Kemampuan keaksaraan yang baik erat hubungannya dengan kemampuan membaca dan menulis anak. Leonhardt, menyatakan bahwa "membaca sangat penting bagi anak. Anakanak yang gemar membaca akan mempunyai kebahasaan yang tinggi. Mereka akan berbicara, menulis dan memahami gagasan-gagasan yang rumit secara lebih baik". Hal ini diperkuat lagi oleh Tom dan Sobol yang menjelaskan bahwa "anak yang sudah memiliki kesiapan membaca di TK akan lebih percaya diri dan penuh kegembiraan". Proses yang dialami dalam membaca adalah berupa penyajian kembali dan penafsiran suatu kegiatan yang dimulai dari mengenali huruf. Anak-anak harus sudah memahami konsep alfabet sebagai bekal kemampuan membaca, menulis dan berbahasanya (Nurbiana, 2012) Kemampuan anak dalam mengenal huruf, khususnya konsep pengenalan huruf sudah harus dilakukan sejak usia dini dan program pengenalan keaksaraan di lembaga PAUD dapat menjadi kegiatan pembelajaran yang amat membantu perkembangan keaksaraan anak. Berdasarkan pengamatan penulis dan hasil wawancara dengan guru kelas di Kelompok A Gemar Ilmu Kecamatan Bulakamba Kabupaten Brebes, terlihat bahwa mayoritas anak belum mampu memahami mengenai konsep huruf. Hal ini terlihat dari kondisi dimana anak tidak mengenal dengan baik huruf latin, anak juga belum mampu menyusun huruf-huruf yang membentuk namanya, anak kurang mampu membedakan mana suara huruf atau suku kata. Pembelajaran yang dilakukan kepada anak dalam pengenalan huruf, hanya diajarkan melalui majalah. Penggunaan majalah yang terlalu sering tidak tepat dalam program pembelajaran anak. Dari wawancara dengan guru, didapat informasi bahwa guru kurang memberikan pengenalan mengenai konsep huruf karena keterbatasan media pembelajaran yang dimiliki sekolah, sehingga pengenalan huruf tidak dilakukan melalui media penunjang belajar serta bermain bagi anak.

\section{Media Kartu Huruf}

Media adalah alat bantu yang digunakan guru dalam proses belajar mengajar. Dengan menggunakan alat bantu dapat menghindari kemungkinan terjadinya kesalahan komunikasi antara guru dan siswa. Media bertujuan untuk membantu guru untuk mengajar dan mempermudah siswa dalam belajar untuk mencapai tujuan pembelajaran.

Kata media berasal dari bahasa latin "medius" yang berarti tengah ,perantara, dan pengantar, dalam Bahasa Arab, media diartikan sebagai perantara atau pengantar pesan dari pengirim pesan kepada penerima pesan. Meurut Djamarah (1995 : 136), media adalah alat bantu apa saja yang dapat dijadikan sebagai penyalur pesan guna mencapai suatu tujuan pembelajaran. Menurut Purawanti dan Eldarni (2001 : 4) ,media merupakan sesuatu yang dapat digunakan untuk menyalurkan suatu informasi sehingga dapat merangsang fikiran ,perasaan, perhatian, dan minat anak sehingga terjadi proses belajar.

Maimunah hasan (2009: 65) mengungkapkan bahwa kartu huruf adalah penggunaan sejumlah kartu sebagai alat bantu untuk belajar membaca dengan cara melihat dan mengingat bentuk huruf dan gambar yang disertai tulisan dari makna gambar pada kartu.

Azhar Arsyad (2005: 119) mengungkapkan bahwa kartu huruf adalah kartu abjad yang berisi gambar, huruf, tanda simbol, yang meningkatkan atau menuntun anak yang berhubungan dengan simbol-simbol tersebut. 
Menurut Kamus Besar Bahasa Indonesia kartu adalah kertas tebal berbentuk persegi panjang. Jadi penggunaan media kartu huruf bisa disimpulkan yaitu media atau perantara yang digunakan oleh seorang guru kepada siswa menggunakan media atau perantara kartu huruf yang berbentuk huruf yang ditulis atau diketik. Seiring berkembangnya jaman sekarang banyak kartu huruf yang dapat dibuat sendiri dengan cara mengetik satu persatu huruf dengan ukuran yang cukup besar agar mudah dilihat kemudian huruf tersebut di cetak dan dilaminating agar tidak mudah rusak dan tahan lama.

Media ini diharapkan efektiv untuk meningkatkan pengenalan huruf bagi siswa khususnya di Pendidikan Anak Usia Dini (PAUD). Oleh karena itu penulis tertarik untuk melakukan observasi yang berjudul "Peningkatan Kemampuan Mengenal Huruf Melalui Media Kartu Huruf" dengan tujuan untuk mengetahui peningkatan kemampuan mengenal huruf pada anak kelompok A Gemar Ilmu Kecamatan Bulakamba Kabupaten Brebes. Pembelajaran menggunakan media ini diharapkan akan menjembatani pemahaman huruf yang abstrak dengan konsep berpikir siswa yang konkret

\section{METODE PELAKSANAAN}

Pengamatan ini dilaksanakan pada Gemar Ilmu Kecamatan Bulakamba Kabupaten Brebes. Waktu pengamatan dilaksanakan pada semester I tahun ajaran 2020/2021. Subjek observasi adalah anak usia 4-5 tahun, kelompok A pada Gemar Ilmu Kecamatan Bulakamba Kabupaten Brebes, yang berjumlah 22 anak terdiri atas 8 laki-laki dan 14 perempuan. Teknik pengumpulan data yang digunakan yakni Observasi atau pengamatan yang merupakan proses pengambilan data dalam penelitian melalui pengamatan langsung secara terstruktur sesuai indikator yang ada dalam pedoman observasi. Serta dokumentasi ialah pengambilan data video dan gambar saat aktivitas berlangsung (Hamzah, Uno, 2011).
Analisis data merupakan kegiatan mengolah, menganalisa dan menginterpretasikan data untuk menemukan informasi hingga memiliki makna dan arti yang jelas sesuai dengan tujuan penelitian (Sanjaya, Wina, 2011: 106). Analisis data yang digunakan dalam penelitian ini adalah dengan menganalisa data melalui penjelasan hasil penelitian secara deskriptif dengan kata-kata.

Analisa data dilakukan berdasarkan hasil observasi yang dikonversi kedalam angkaangka dan dipresentasekan sehingga didapat data kuantitatif yang menunjukkan ketuntasan individu, klasikal yang mengarah pada hasil penelitian. Adapun standar penilaian dari pedoman observasi yang digunakan peneliti akan menggunakan standar penilaian sebagai berikut.

Tabel 1. Acuan Penilaian Pedoman Observasi

\begin{tabular}{lllr}
\hline Skor & Nilai Mutu & Indikator & \\
\hline & & & \\
1 & Belum & Jika dalam & pencapaian \\
& Berkembang & indikator & yang \\
& (BB & ditetapkan & pada \\
& & pelaksanaannya harus \\
& & dengan bimbingan atau \\
& & dicontohkan guru
\end{tabular}

2 Mulai Jika dalam pencapaian Berkembang indikator yang (MB) ditetapkan masih harus diingatkan atau dibantu guru

\begin{tabular}{lll}
\hline 3 & Berkembang & Jika anak dalam \\
Sesuai & pencapaian indikator \\
harapan & yang ditetapkan sudah \\
(BSH) & dapat melakukannya \\
& secara mandiri dan \\
& konsisten tanpa harus \\
& diingatkan dan \\
& dicontohkan oleh guru
\end{tabular}

\begin{tabular}{|c|c|c|}
\hline \multirow[t]{2}{*}{4} & Berkembang & Jika anak dalam \\
\hline & $\begin{array}{l}\text { Sangat Baik } \\
\text { (BSB) }\end{array}$ & $\begin{array}{lr}\text { pencapaian indikator } \\
\text { yang ditetapkan sudah } \\
\text { dapat melakukannya } \\
\text { secara mandiri dan } \\
\text { dapat } & \text { membantu } \\
\text { temannya } & \text { yang belum } \\
\text { mampu } & \text { mencapai } \\
\text { indikator } & \text { yang }\end{array}$ \\
\hline
\end{tabular}

Penggunaan Kartu Huruf dan Permainan Mencari Kartu Huruf Untuk Peningkatan Pengenalan Huruf (Muhamad Toha, Armyta Puspitasari, Ubaedillah, Farhan Saefudin Wahid, Laelia 


\section{ditetapkan. \\ Sumber: Tim Direktorat Pembinaan PAUD (2015)}

Rumus yang digunakan untuk mencari persentase dalam penelitian ini adalah sebagai berikut.

$N P=\frac{\mathscr{R}}{S M} \times 100 \%$

(Purwanto, 2006)

Keterangan:

NP : Nilai persentase yang dicari atau yang diharapkan

$\mathrm{R} \quad$ : Skor mentah yang diperoleh anak

SM : Skor maksimum ideal dari tes yang bersangkutan

100 : Bilangan tetap

Setelah diperoleh skor setiap anak dan nilai rata-ratanya secara klasikal, kemudian hasilnya diinterpretasikan pada skala kualifikasi sebagai berikut.

Tabel 2. Interval dan Kategori Hasil Belajar

\begin{tabular}{ccc}
\hline No. & Interval & Predikat \\
\hline 1 & $80-100$ & Sangat baik \\
\hline 2 & $70-79$ & Baik \\
\hline 3 & $60-69$ & Cuku \\
\hline 4 & $50-59$ & Kurang \\
\hline 5 & $0-49$ & Kurang sekali \\
\hline Sumber: Syah (2012)
\end{tabular}

Berikut adalah kisi-kisi pedoman observasi yang digunakan dalam pengamatan ini, dimana selanjutnya akan dijadikan panduan untuk menyusun pedoman observasi untuk mengamati perkembangan kemampuan mengenal huruf anak dalam kegiatan pembelajaran dengankartu huruf.

Tabel 3. Kisi-Kisi Pedoman Observasi

\section{Variabel Indikator}

Kemampuan Menyebutkan simbol huruf dengan benar

\begin{tabular}{ll}
\hline Mengenal & $\begin{array}{l}\text { Menunjukkan simbol huruf } \\
\text { dengan benar }\end{array}$ \\
\hline
\end{tabular}

\begin{tabular}{|c|c|c|}
\hline Huruf & $\begin{array}{l}\text { Menghubungkan } \\
\text { dan huruf awal } \\
\text { benar }\end{array}$ & $\begin{array}{l}\text { gambar } \\
\text { dengan }\end{array}$ \\
\hline & $\begin{array}{l}\text { Menuliskan huruf } \\
\text { benar }\end{array}$ & dengan \\
\hline
\end{tabular}

\section{HASIL DAN PEMBAHASAN}

Hasil pengamatan pada saat sebelum diterapkannya pembelajaran mengenal huruf dengan kartu huruf dengan pembelajaran lewat permainan serta nyanyian-nyanyian, terdapat kemampuan mengenal huruf yang kurang baik pada siswa kelompok A Gemar Ilmu Kecamatan Bulakamba Kabupaten Brebes. Terlihat dari perolehan hasil rata-ratanya berada pada $45,44 \%$ yang tergolong pada kategori kurang sekali. Pembelajaran yang dilakukan guru dalam mengajar sangat monoton bagi anak. Pembelajaran melalui penggunaan majalah dengan cara anak mengerjakan sesuai dengan perintah dari lembar kerja majalah yang kemudian anak diajak untuk menyebutkan satu-satu huruf yang terdapat dalam kalimat. Guru tidak terlalu memperhatikan kemampuan anak, karena guru menyebutkan kemudian anak mengikuti apa yang diucapkan oleh gurunya. Dan sebagian anak kurang antusias ketika pembelajarannya seperti demikian. Sehingga perhatian anak teralihkan oleh hal lain disekitarnya. Berdasarkan pengamatan pada kemampuan mengenal huruf anak pada pengetesan pertama didapat hasil penelitian sebagai berikut.

Tabel 4. Rekapitulasi Pretest

\begin{tabular}{ccc}
\hline Kriteria & Jumlah Anak & Presentase \\
\hline BB & 2 & $9,1 \%$ \\
\hline MB & 10 & $45,46 \%$ \\
\hline BSH & 7 & $31,81 \%$ \\
\hline BSB & 3 & $13,63 \%$ \\
\hline Jumlah & 22 & $100 \%$ \\
\hline
\end{tabular}

Berdasarkan persentase kemampuan mengenal huruf hasil pengamatan pada saat pretest dapat diketahui bahwa tingkat kemampuan mengenal huruf diperoleh sebesar $45,44 \%$ terlihat dari jumlah total 10 
orang siswa yang mencapai berkembang sesuai harapan dan berkembang sangat baik. Setelah diterapkan pembelajaran dengan menggunakan media kartu huruf, melalui nyanyian serta permainanpermainan, terdapat peningkatan pada kemampuan mengenal huruf anak. Perolehan rata-rata pengetesan setelah dilakukan pembelajaran dengan media kartu huruf sebesar 86,26\% yang menunjukan pada kategori sangat baik. Maka dihitung ratarata hasil observasi kemampuan mengenal huruf pada anak dalam tabel berikut:

Tabel 5. Rekapitulasi Posttest

\begin{tabular}{ccc}
\hline Kriteria & Jumlah Anak & Presentase \\
\hline BB & 0 & 0 \\
\hline MB & 3 & $13,64 \%$ \\
\hline BSH & 13 & $59,09 \%$ \\
\hline BSB & 6 & $27,27 \%$ \\
\hline Jumlah & 22 & $100 \%$ \\
\hline
\end{tabular}

Berdasarkan persentase pada tabel 5 maka kemampuan mengenal huruf pada saat posttest dapat dinyatakan mengalami peningkatan menjadi $86,36 \%$ terlihat dari jumlah total 19 orang siswa yang mencapai berkembang sesuai harapan dan berkembang sangat baik.

Tabel 6. Rata-rata Hasil Observasi Kemampuan Mengenal Huruf

\begin{tabular}{ccc}
\hline Subjek & Pretest & Posttest \\
\hline $\begin{array}{c}\text { Kelas A anak usia } \\
\text { 4-5 tahun }\end{array}$ & $45,44 \%$ & $86,26 \%$ \\
\hline
\end{tabular}

Berdasarkan tabel 6 tingkat keterlaksanaan kemampuan mengenal huruf pada anak kelompok A Gemar Ilmu Kecamatan Bulakamba Kabupaten Brebes terjadi peningkatan dari yang mulanya $45,44 \%$ dengan kategori kurang sekali, setelah dilakukan pembelajaran dengan media kartu huruf menjadi $86,26 \%$ dengan kategori sangat baik.

Berdasarkan

pelaksanaan

pembelajaran melalui media kartu huruf diperoleh hasil bahwa kegiatan pembelajaran mengenal huruf berjalan dengan baik dan mampu memberikan peningkatan terhadap kemampuan mengenal huruf anak kelompok A Gemar Ilmu Kecamatan Bulakamba Kabupaten Brebes. Proses pembelajaran yang direfleksikan sebagai berikut, diantaranya, (1) Anak-anak telah mampu menunjuk dan mengambil huruf sesuai perintah dengan benar. (2) Anak-anak mampu mengucapkan bunyi huruf dengan tepat dan artikulasi yang jelas. (3) Hasil perhitungan persentase pada posttest adalah 86,36\% menunjukkan tercapainya indikator keberhasilan yang ditetapkan yaitu $75 \%$. Pembelajaran dengan menggunakan media sangat besar pemanfaatannya dalam pengenalan huruf terhadap anak usia dini. Selain itu juga penggunaan media penunjang lain memberikan hasil yang lebih baik dan proses pembelajaran yang lebih menarik bagi anak. Media alphabet melaui papantulis dan media alphabet berupa gambar memang sangat mendukung pembelajaran pengenalan huruf abjad. Akan tetapi, akan lebih baik juga jika guru mengombinasikan media tersebut dengan media audio visual sebagai contoh video, DVD, dan lain-lain. Jadi guru tidak hanya memberikan teori saja, tetapi juga memberikan pembelajaran berupa praktik pengenalan huruf abjad dengan menggunakan media audio visual (Yosa, 2012:9). Selain itu, dukungan dari keluarga pun sangat menunjang suksesnya pembelajaran anak terhadap perkembangan serta kemampuan dalam pengenalan huruf, Menurut pendapat Djaali Situasi keluarga (ayah, ibu, saudara, adik, kakak, serta famili) sangat berpengaruh terhadap keberhasilan anak dalam keluarga. Pendidikan orang tua, status ekonomi, rumah kediaman, persentase hubungan orang tua, perkataan dan bimbingan orang tua mempengaruhi pencapaian hasil belajar anak. (Tatik, 2012)

\section{KESIMPULAN}

Berdasarkan hasil pengamatan kemampuan mengenal huruf anak kelompok A Kober Darussalam Ibun melalui pembelajaran dengan menggunakan media kartu huruf dapat disimpulkan bahwa metode 
pembelajaran dengan menggunakan kartu huruf dalam mengenal huruf bagi anak kelompok A Kober Darussalam Ibun memberikan pengaruh yang signifikan. Terlihat dari hasil persentase penilaian ratarata sebelum pembelajaran atau pada saat posttest berada dalam kategori kurang sekali. Kemudian setelah dilakukan pembelajaran kemampuan mengenal huruf anak meningkat berada dalam kategori sangat baik. Firdaus Peningkatan Kemampuan Mengenal 73 JAPRA Volume 2, Nomor 2, Maret 2019 Berdasarkan kesimpulan di atas ada beberapa saran yang ingin peneliti uraikan yaitu: (1) Pelaksanaan pembelajaran anak usia dini harus sesuai dengan ketentuan bahwasanya anak harus belajar sambil bermain, sehingga dalam mengenalkan huruf kepada anak dilakukan melalui permainan-permainan serta nyanyian-nyanyian yang mampu membuat anak lebih antusias. (2) Sekolah harus menyediakan sedikitnya media pembelajaran yang menunjang bagi anak dalam belajar, seperti kartu huruf, alat matematis, serta hal-hal lain yang menarik minat anak untuk belajar. (3) Guru harus lebih kreatif dalam memberikan pengajaran, membawa suasana belajar menjadi menyenangkan dan lebih kondusif lagi, sesuai dengan ketentuan kegiatan belajar mengajak anak usia dini yang telah ditentukan. Implikasi dari kegiatan pembelajaran kartu huruf dapat meningkatkan kemampuan anak mengenal huruf, sehingga kegiatan ini dapat dilakukan di lembaga PAUD

\section{DAFTAR PUSTAKA}

Azhar Arsyad. (2005). Media Pembelajaran. Jakarta: Raja Grafindo Persada.

Djamarah. 2002. Strategi Belajar Mengajar. Jakarta: Rineka Cipta

Lingkup perkembangan bahasa, aspek keaksaraan, Lampiran 1 Peraturan Menteri Pendidikan dan Kebudayaan No.137 tahun 2014 tentang Standar Nasional PAUD
Maimunah Hasan. (2009). Pendidikan Anak Usia Dini. Yogyakarta: Diva Press.

Nurbiana, D. (2012). Metode Pengembangan Bahasa. Jakarta: Universitas Terbuka.

Peraturan Menteri Pendidikan dan Kebudayaan Nomor 137 Tahun 2014 tentang Standar Nasional Pendidikan Anak Usia Dini.

Purwanto, N. (2006). Prinsip-Prinsip dan Teknik Evaluasi Pengajaran. Bandung: Remaja Rosdakarya, h.102

Sanjaya, W. (2011). Penelitian Tindakan Kelas. Jakarta: Kencana Prenada Media Group, h.106

Tatik, A. (2012). Peningkatan Kemampuan Membaca Permulaan Melalui Penggunaan Media Gambar, https://media.neliti.com/media/public ations/118389-ID-

peningkatankemampuan-membacapermulaan.pdf (diunduh tanggal 10 Februari 2019).

Tim Direktorat Pembinaan PAUD. (2015) .Penilaian Pembelajaran Pendidikan Anak Usia Dini. Jakarta : Direktorat Pembinaan PAUD Dierjen PAUD dan pendidikan Masyarakat Kementrian Pendidikan dan Kebudayaan, h.5

Uno, H. B., Nina Lamatenggo, Satria M.A Koni. (2011). Menjadi Peneliti PTK Yang Profesional. Jakarta: Bumi Aksara

Yosa. (2012). Analisis Pembelajaran Pengenalan Huruf dengan Menggunakan Media Alfabet pada Anak Usia 5-6 Tahun. Skripsi. Pontianak : Universitas Tanjungpura well, J. (2014). Research design: Qualitative, quantitative, and mixed methods approaches, (4thed). Belmont, CA: SAGE Publications, Inc. 